\title{
Thermal Performance Evaluation of Domed Roofs
}

\author{
Ahmadreza K. Faghih ${ }^{1, *}$, Mehdi N. Bahadori ${ }^{2}$ \\ ${ }^{1}$ Yazd University, Yazd, Iran \\ ${ }^{2}$ Sharif University of Technology, Tehran, Iran \\ * Corresponding author. Tel: +98 351 8122561, Fax: +98 351 8210699, E-mail: faghih@yazduni.ac.ir
}

\begin{abstract}
Domed roofs (DRs) have been used in Iran and many other countries to cover large buildings such as mosques, shrines, churches, schools, etc. They have been also employed in other buildings like bazaars or market places in Iran due to their favorable thermal performance. The aim of this research is to study about DRs thermal performance in order to determine how they can be helpful in reducing the maximum air temperature of inside buildings during the warm seasons considering all parameters like air flow around them, solar radiation, radiation heat transfer with the sky and the ground as well as some openings on the building. The results of the study show that the thermal performance of the investigated DR is better than the building with flat roof (FR), particularly when the dome is covered with glazed tiles. In addition to their aesthetic values, domes covered with glazed tiles have thermal benefits of keeping the inside air of these buildings relatively cool during the summer. Moreover, openings cause passive air flow inside building, which is helpful for human comfort.
\end{abstract}

Keywords: domed roof, thermal performance, air flow, solar radiation, numerical simulation, thermal network

\section{Nomenclature}

C Specific heat. $J . k g^{-1} K^{-1}$

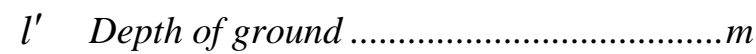

$C_{D}$ Discharge coefficient.

$m \quad$ Inside building air mass ........................... $\mathrm{kg}$

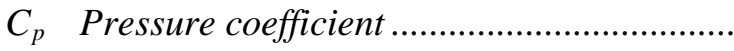

$D \quad$ Wall or roof thickness................................. $m$

F View factor

$\dot{q} \quad$ Heat transfer rate .................................. $m^{-2}$

H,h Height .................................................... $m$

$R \quad$ flow resistance .............................. kg. $\mathrm{m}^{-4} \cdot \mathrm{s}^{-1}$

$T$ Temperature .............................................

$\dot{V} \quad$ Volumetric air flow rate ...................... $\mathrm{m}^{3} . \mathrm{s}^{-1}$

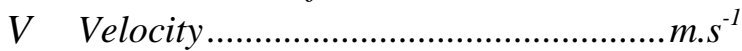

\section{Subscript}

$R \quad$ Roof

$W$ Wall, roof.

$H$ Height.

a Air.....

abs Absorbed.

c Convection

dp Dew point.

e East

$f$ Floor

$g$ Ground.......

$t \quad$ Time.......................................................

$\beta$ Slope.

$\varepsilon$ Surface emittance

$\varepsilon_{s} \quad$ Sky emissivity.

$\rho \quad$ Density..................................................... ${ }^{-3}$

$\sigma \quad$ Stefan-Boltzmann constant................ w. $m^{-2} \cdot k$

\section{Introduction}

DRs have traditionally been used throughout the world to cover large areas. Solar energy absorbed by a DR causes its temperature to rise above the ambient air temperature. Wind blowing over the dome increases the convection heat transfer to the ambient air. Furthermore, the heat loss from the roof is increased by thermal radiation to the sky. The rest of the heat absorbed by the dome is conducted through the dome material, and is finally transferred to the 
inside air by convection, and to the interior walls by radiation. The geometry of these roofs causes the wind velocity to increase over them, resulting in an increase in the convection heat transfer coefficient. Furthermore, the heat transfer from these roofs is increased by the fact that their areas are greater than the comparable flat ones. In addition to their structural applications, DRs have been employed in Iran for natural ventilation and passive cooling of buildings. A cross section of a typical DR employed in such applications is shown in Fig. 1.

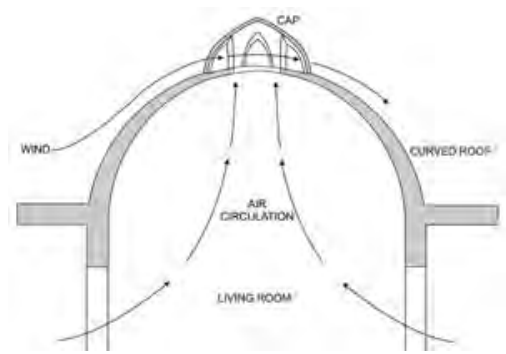

Fig. 1. Cross section of a typical DR, with air circulation in and over it [1]

In 1978, Bahadori introduced the important role of DRs in providing cold water in cistern as well as indoors air condition in warm and dry areas in Iran [1]. Konya [2] showed that the temperature of domed roof buildings (DRBs) is lower compared to flat ones. Mainstone [3] professed that the main reason of lower temperature of inside DRBs in comparison with FRs is the higher ground and sky reflected radiation heat loss. Olgyay [4] guessed that lower indoor air temperature in DRBs is due to the lower absorbed solar radiation in comparison with FRs. Tang [5] showed greater solar radiation and heat transfer through DRs and refused what Bahadori [1] had been asserted before. The aim of this research is to study about DRs thermal performance considering all parameters like air flow, solar radiation, radiation heat transfer with the sky and the ground as well as some openings on the building by using the thermal network method. Constant wind velocity and direction is assumed, and the IAT during a day is the comparison index.

We investigated air flow over domed and FRBs numerically [6] and experimentally [7] to find proper data for our own study. In these studies we consider the three-dimensional model of the dome of the School of Theology (the reference dome) shown in Fig. 2 which is located in Yazd, Iran (a city with very high solar radiation) with a specified boundary layer air flow. For this study, the absorbed solar radiation reported by the authors in [8] for the reference dome and the corresponding flat one with the same base area is used. In [8] it is found that DRs receive more solar radiation in comparison with flat ones.
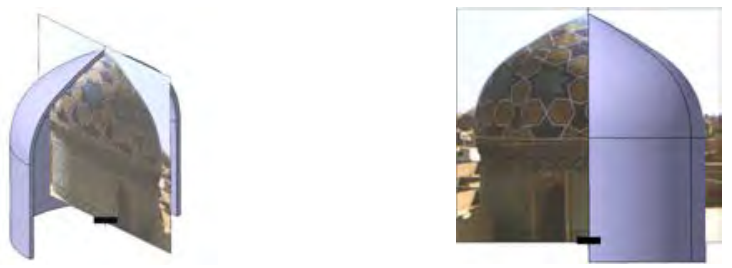

Fig. 2. Model of the reference DR

\section{Absorbed Heat}

In Eq. (1), solar radiation $\left(Q_{s}\right)$ in each hour is assumed to be constant and is equal to its exact amount in the middle of the specified hour. The convection heat transfer between the ambient air and the outer surface of the building is defined in Eq. (2) [9].

$Q_{a b s}=Q_{s}+Q_{c}+Q_{r s}+Q_{r g}$ 
$Q_{c}=h_{0} A\left(T_{a o}-T_{W}\right)$

$h_{o}=\sqrt{h_{n}{ }^{2}+\left[2.38 V_{W}^{0.89}\right]^{2}}$

$\mathrm{V}_{\mathrm{W}}$ is the air flow velocity near the wall which is defined by the authors numerically and experimentally in $[6,7]$. Boundary layer air velocity profile near the ground defined in Eq. (4) [10] is assumed in those studies. $V_{400}$ is the wind velocity at height $400 \mathrm{~m} . \mathrm{h}_{\mathrm{n}}$ in Eq. (3) is the natural convection coefficient defined in Eq. (5) and (6) for upward and downward heat transfer respectively [11].

$\frac{V_{h}}{V_{400}}=\left[\frac{h}{400}\right]^{0.28}$

$h_{n}=9.482 \frac{\sqrt[3]{|\Delta T|}}{7.238-|\operatorname{Cos} \beta|}$

$h_{n}=1.810 \frac{\sqrt[3]{|\Delta T|}}{1.382+|\operatorname{Cos} \beta|}$

$\beta$ is the slope of each surface and $\Delta T$ is the temperature difference between the ambient and each surface in the specified time. The ambient air temperature is defined using Eq. (7) [12].

$T_{a o}=\left(\frac{T_{m}+T_{n}}{2}\right)+\left(\frac{T_{m}-T_{n}}{2}\right) \cdot \operatorname{Cos}\left(180\left(\frac{t-15}{12}\right)\right)$

The radiation heat transfer between the outer surface of the building and the sky and the ground is defined by Eq. (8) and (11). Note that $\varepsilon$ is assumed to be $0.85, \mathrm{~T}_{\mathrm{s}}$ is the sky temperature defined in Eq. (9) [13] and $\mathrm{T}_{\mathrm{g}}$ is the ground temperature which is similar to the ambient temperature at each time.

$Q_{r s}=\varepsilon \sigma\left(T_{S}{ }^{4}-T_{W}{ }^{4}\right)\left(\frac{1+\operatorname{Cos} \beta}{2}\right)$

$T_{S}=\varepsilon_{S}^{0.25}\left(T_{a o}+273.15\right)$

$\varepsilon_{S}=0.74+0.006 T_{d p}$

$Q_{r g}=\varepsilon \sigma\left(T_{g}{ }^{4}-T_{W}{ }^{4}\right)\left(\frac{1-\operatorname{Cos} \beta}{2}\right)$

\section{Boundary Conditions}

The outer surface: This surface receives absorbed heat transfer which is discussed in Section 2. The absorbed coefficient of the ordinary material and the glazed tile are assumed to be 0.8 and 0.4 respectively. The FR and the wall are covered with the ordinary material, but both the ordinary material and the glazed tile are considered to cover the DR. wall thickness: Conduction heat transfer parameters are $\mathrm{k}=1.4 \mathrm{w} \cdot \mathrm{m}^{-1} \cdot \mathrm{k}^{-1}, \mathrm{C}=880 \mathrm{~J} \cdot \mathrm{kg}^{-1} \cdot \mathrm{K}^{-1}$, and $\rho=2300$ 
kg. $\mathrm{m}^{-3}$. The inner surface and the floor: For simplification, constant convection heat transfer coefficient $\left(3 \mathrm{w} \cdot \mathrm{m}^{-2} \cdot \mathrm{k}^{-1}\right)$ is considered. The wall base: assumed to be insulated.

\section{Initial Conditions}

The initial temperature of the walls, roof, floor, and inside air are equal to the ambient air temperature at initial time, which is 6 A.M. lumped system is considered for the IAT and changing of this parameter can be determined by Eq. (12). $\Delta t$ is time step, $\mathrm{m}$ is the inside building air mass, and $\mathrm{C}_{\mathrm{v}}$ is assumed to be $717 \mathrm{~J}_{\mathrm{kg}}{ }^{-1} \cdot \mathrm{K}^{-1}$. Deviations of the IAT during a specified day (6 August) in the city of Yazd, in the central desert region of Iran (31.54 N; 54.17 E; maximum air temperature: $37.9{ }^{\circ} \mathrm{C}$; minimum air temperature: $21.7{ }^{\circ} \mathrm{C}$; dew point: 8 ${ }^{\circ} \mathrm{C}$ ), for the domed and the FRBs are compared.

$$
\frac{\Delta T_{a i}}{\Delta t}=\frac{\sum h_{i} A\left(T_{W i}-T_{a i}\right)}{m C_{v}}
$$

\section{Thermal Network}

A cylinder with the height of $3 \mathrm{~m}$ and diameter of $6 \mathrm{~m}$ is assumed to be a building for both models (Fig. 2). The height of the dome and the wall thickness in both models are $3 \mathrm{~m}$ and $15 \mathrm{~cm}$ respectively. In the air flow study of these models $\mathrm{V}_{400}=48.6 \mathrm{~m} / \mathrm{s}$, therefore according to Eq. (4) the air flow velocity on top of the DR $(6 \mathrm{~m})$ is $15 \mathrm{~m} / \mathrm{s}\left(\mathrm{Re}=5.8 \times 10^{5}\right)$. In this method, the geometry of the building has been simplified to take the radiation heat transfer between inner surfaces of the building into account. Fig. 3 shows the simplified geometry. All view factors can be determined in this simplified geometry. In this geometry, the heights are similar to the actual model, but the dome is assumed as a triangular pyramid. Each surface of this pyramid faces to the north, south, east or west. To have similar base area, the base width and length are assumed to be $5.32 \mathrm{~m}$.

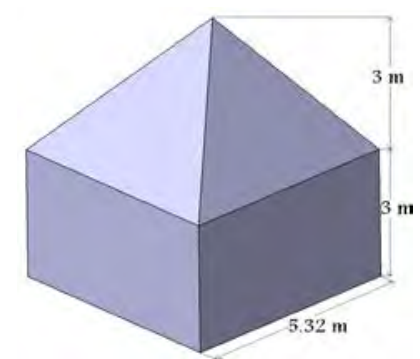

Fig. 3. The simplified model of the DRB used in the thermal network method

\subsection{Heat Transfer Equations}

The thermal network of the DRB used in this study consists of 18 nodes. 8 nodes are located on the outer surfaces ( 4 nodes on the roof surfaces and 4 nodes on the wall surfaces), 8 nodes are located on the inner surfaces, 1 node representing the inside building air and 1 node representing the floor. There are 12 nodes in the thermal network of the FR. Fig. 4 shows the thermal network of the southern roof in the simplified DRB. As shown in Fig. 4, the inner surface of the southern roof has radiation heat transfer with the three other inner surfaces of the roof (north, east and west) as well as four inner surfaces of the wall. There is a convection heat transfer with the inside building air as well. Eq. (13) and (14) show the energy balance of the inner and outer nodes of the southern roof. 


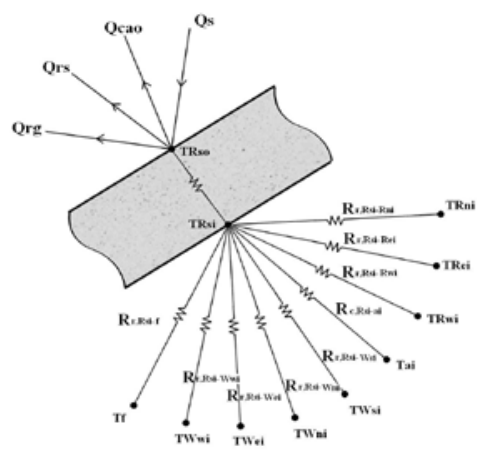

Fig. 4. The thermal network of the southern roof in the simplified DRB

$$
\begin{aligned}
& \left(\dot{q}_{s}+\dot{q}_{c a o}+\dot{q}_{r s}+\dot{q}_{r g}\right)+k \frac{T_{R s i}-T_{R s o}}{D}=\rho_{W} \frac{D}{2} C \frac{T_{R s o}^{\prime}-T_{R s o}}{\Delta t} \\
& k A_{R s i} \frac{T_{R s o}-T_{R s i}}{D}+\frac{A_{R n i} \sigma\left(T_{R n i}{ }^{4}-T_{R s i}{ }^{4}\right)}{\frac{1-\varepsilon_{R n i}}{\varepsilon_{R n i}}+\frac{1}{F_{R n i-R s i}}+\frac{1-\varepsilon_{R s i}}{\varepsilon_{R s i}} \frac{A_{R n i}}{A_{R s i}}}+\ldots+\frac{A_{f} \sigma\left(T_{f}{ }^{4}-T_{R s i}{ }^{4}\right)}{\frac{1-\varepsilon_{f}}{\varepsilon_{f}}+\frac{1}{F_{f-R s i}}+\frac{1-\varepsilon_{R s i}}{\varepsilon_{R s i}} \frac{A_{f}}{A_{R s i}}}+h_{c, R s i-a i} A_{R s i}\left(T_{a i}-T_{R s i}\right)=\rho_{W} A_{R s i} \frac{D}{2} C \frac{T_{R s i}^{\prime}-T_{R s i}}{\Delta t}
\end{aligned}
$$

In Eq. (13), $\dot{q}_{s}$ is the averaged absorbed solar radiation of the quarter of the dome face to the south. $\dot{q}_{c a o}$ is the convection heat transfer which is calculated based on Eq. (2) and (3). Air flow velocity is the average air velocity near the quarter of the dome face to the south. Energy balance equations for all nodes are derived similarly. Emittance of all surfaces is assumed to be 0.85 in this study. Fig. 5 shows the thermal network of the floor. As shown in Fig. 5, there is a conduction heat transfer between the floor and the depth of the ground $\left(l^{\prime}=5 \mathrm{~m}\right)$ [14] with the annually averaged temperature $(\bar{T})$ of the under study area (Yazd) which is reported 18 ${ }^{\circ} \mathrm{C}$. Eq. (15) shows the energy balance of the floor node.

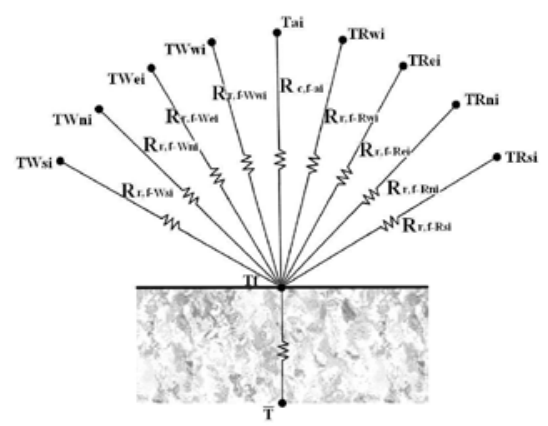

Fig. 5. The thermal network of the floor

$$
k_{f} A_{f} \frac{\bar{T}-T_{f}}{l^{\prime}}+\frac{A_{R s i} \sigma\left(T_{R s i}{ }^{4}-T_{f}{ }^{4}\right)}{\frac{1-\varepsilon_{W}}{\varepsilon_{W}}+\frac{1}{F_{R s i-f}}+\frac{1-\varepsilon_{f}}{\varepsilon_{f}} \frac{A_{R s i}}{A_{f}}}+\ldots+h_{c, f-a i} A_{f}\left(T_{a i}-T_{f}\right)=\rho_{f} A_{f} \frac{l^{\prime}}{2} C_{f} \frac{T_{f}^{\prime}-T_{f}}{\Delta t}
$$

In this study $\rho_{f}=1300 \mathrm{~kg} \cdot \mathrm{m}^{-3}, \mathrm{k}_{\mathrm{f}}=0.75 \mathrm{w} \cdot \mathrm{m}^{-1} \cdot \mathrm{K}^{-1}$ and $\mathrm{C}_{\mathrm{f}}=970 \mathrm{~J} \cdot \mathrm{kg}^{-1} \cdot \mathrm{K}^{-1}$. Eq. (16) shows the energy balance of the inside building air. In this Eq. $\dot{m}$ is the air mass flow rate (kg.s $\left.{ }^{-1}\right)$ which is equal to zero, when there is no opening on the building.

Energy balance equations define all temperatures for next time steps. This method is not sensitive to the time step. We consider the time step of 15 seconds for both the domed and the FRBs. The simulation starts from 6 A.M. and it continues until we get $0.1{ }^{\circ} \mathrm{C}$ difference between the IAT for the specified day (6 August) and a day after that at 6 A.M. 
$h_{c, a i-f} A_{f}\left(T_{f}-T_{a i}\right)+h_{c, a i-R s i} A_{R s i}\left(T_{R s i}-T_{a i}\right)+\ldots+\dot{m} C_{p}\left(T_{a o}-T_{a i}\right)=\rho_{a} V C_{v} \frac{T_{a i}^{\prime}-T_{a i}}{\Delta t}$

\subsection{Thermal Network Results}

Fig. 6 shows the sky, the ambient, and the IAT for the DRB covered with the ordinary material, when the wind direction is south. There are similar figures for other cases, but they are not presented here for the sake of brevity. Table 1 compares the maximum IAT. The reference DRB has better thermal performance in comparison with the FRB with similar conditions. It can be also seen that using glazed tiles improves DRB thermal performance. Wind direction does not have considerable affect on the thermal performance of buildings.

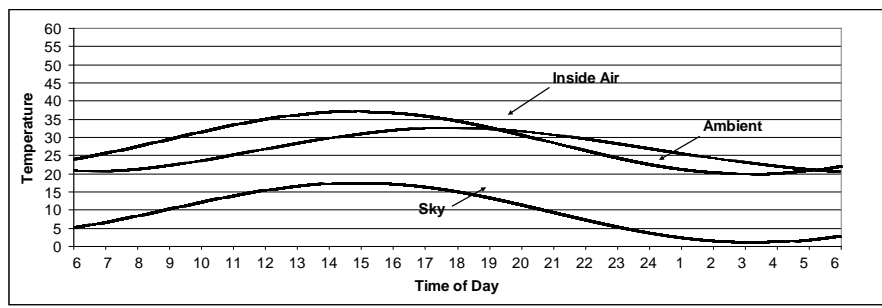

Fig. 6. The sky, the ambient, and the IAT for the DRB covered with the ordinary material

Table 1. Maximum air temperature, using the numerical simulation method

\begin{tabular}{|c|c|c|c|c|}
\hline Time & Max. Temperature & Roof Absorb Coefficient & Type of Roof & Wind Direction \\
\hline $16: 43$ & 37.30 & 0.8 & Flat & \multirow{3}{*}{ South } \\
\hline $17: 35$ & 37.09 & 0.8 & Dome & \\
\hline $17: 35$ & 36.04 & 0.4 & Dome & \\
\hline
\end{tabular}

Fig. 7 shows the deviation of all heat transfer to the outer surface of the DRB covered with the ordinary material, when the wind direction is south. Convection heat transfer between the outer surface of the building and the ambient air is always negative except from 4.5 to 7 A.M., which shows that most of the time the walls and the roof are warmer than the ambient.

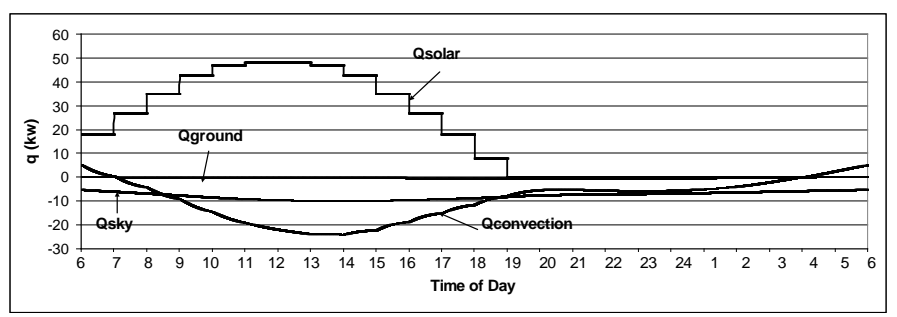

Fig. 7. The deviation of all kinds of heat transfer to the outer surface of the DRB

\subsection{Openings}

To investigate the effect of openings, we consider the model shown in Fig. 8. This Fig. depicts the locations and dimensions of two openings on the wall and one hole on its apex. One opening faces to the wind flow (windward) and the second one is behind (leeward). In the following, we study two scenarios which are "no wind flow" and "with wind flow". 


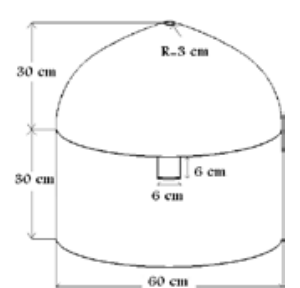

Fig. 8. The locations and dimensions of two openings on the wall and one hole on its apex

\subsubsection{No Wind Flow}

Air temperature difference causes air flow in this condition. Air flow rate can be defined by Eq. (17) or (18) [11]. $C_{D}$ in these equations is opening discharge coefficient [11]. Considering Eq. (16), as well as the air flow rate we can define the IAT in the next time step $\left(T_{a i}^{\prime}\right)$. The convection heat transfer coefficient between the inner surface of the building and the IAT is assumed to be always $4 \mathrm{w} \cdot \mathrm{m}^{-2} \cdot \mathrm{K}^{-1}$.

$$
\begin{array}{ll}
\dot{V}=C_{D} A \sqrt{2 g \Delta H \frac{\left(T_{a i}-T_{a o}\right)}{T_{a i}}} & T_{a o}>T_{a i} \\
\dot{V}=C_{D} A \sqrt{2 g \Delta H \frac{\left(T_{a o}-T_{a i}\right)}{T_{a o}}} & T_{a o}<T_{a i} \\
C_{D}=0.4+0.0045\left|T_{a i}-T_{a o}\right| &
\end{array}
$$

The results show that the maximum IAT in this scenario is 42.95 which is at $16: 27$. In the same situation when the wind direction was south in section 5.2, the maximum IAT was 37.09. This means that without wind flow, openings cannot be helpful. Furthermore, we see that the convection heat transfer reduces in this situation. It is due to the reduction in the air flow velocity near the building's roof and wall. Increasing in radiation heat transfer with the sky is sensible because the temperature difference between walls and the sky increases.

\subsubsection{With Wind Flow}

In the wind flow scenario, both air temperature difference and air pressure difference between openings cause air flow inside the building. To define the air flow caused by pressure difference, flow network method is used in this study. In this method, air volumetric flow rate from each opening (j) is defined by Eq. (20). Where $P_{i}$ is the inside air pressure and $P_{j}$ is the air pressure on the related opening. $\mathrm{P}_{\mathrm{j}}$ can be determined by Eq. (21). $\mathrm{C}_{\mathrm{pj}}$ is defined in previous surveys $[6,7] . \mathrm{C}_{\mathrm{p}}$ is assumed to be $-1.1,1$, and 0.3 for the hole on apex, windward opening, and leeward opening respectively. In this study all openings discharge coefficients are assumed to be 0.65 . The inside air pressure coefficient $\left(\mathrm{C}_{\mathrm{pi}}\right)$ is defined by using Eq. (21) with i as its index. Combining Eq. (20) to (22), the air flow rate of the opening can be found by Eq. (23).

$$
\begin{aligned}
\dot{V}_{j} & =\frac{P_{j}-P_{i}}{R_{i j}} \\
P_{j} & =C_{p j} \frac{1}{2} \rho V_{0}^{2} \\
R_{i j} & =\frac{\sqrt{\frac{1}{2} \rho\left(P_{j}-P_{i}\right)}}{A_{j} C_{d j}} \\
\dot{V}_{j} & =A_{j} C_{d j} V_{0}\left[\frac{C_{p j}-C_{p i}}{\sqrt{\left|C_{p j}-C_{p i}\right|}}\right]
\end{aligned}
$$


Using Eq. (21) with i as its index and (23) and try and error method, $\mathrm{C}_{\mathrm{pi}}$ and $\dot{V}_{j}$ can be determined. For the wind velocity profile similar to (4), the network flow method leads to the value of $1.28 \mathrm{~m}^{3} / \mathrm{s}$. We use the reference velocity of $15 \mathrm{~m} / \mathrm{s}$. This amount is assumed to be constant during the day. The convection heat transfer coefficient between the inner surface of the building and the inside building air is assumed to be constant and equal to $6 \mathrm{w} \cdot \mathrm{m}^{-2} \cdot \mathrm{K}^{-1}$. This coefficient is the greatest one in comparison with the other cases ( 3 and $4 \mathrm{w} \cdot \mathrm{m}^{-2} \cdot \mathrm{K}^{-1}$ ) due to the higher air flow velocity near the inner surface of the building. Maximum air temperature in this condition is 37.46 occurred at 15:09. In similar conditions with no openings, maximum air temperature was 37.09. So again in the wind flow condition the thermal performance of the building with no opening is better, however the air flow inside the building caused by openings can be helpful for human comfort on warm days.

\section{Conclusions}

Based on the analysis carried out the following conclusion can be made: Thermal performance of the DRB under investigation is better than the building with FR on warm days, particularly when the dome is covered with glazed tiles. Wind flow direction is not an important parameter in decreasing room temperature of the DRB of the specified cases. For no wind flow condition, the FRB performs better than the DR one. The passive air flow inside the DRB caused by openings can be helpful for human comfort on warm days.

\section{References}

[1] M. N. Bahadori, Passive Cooling Systems in Iranian Architecture, Scientific American, Vol. 238, 1978, pp. 144-154.

[2] A. Konya, Design Primer for Hot Climate, the Architectural Press, 1980, pp. 3-42.

[3] R. J. Mainstone, Developments in Structural Form, M.L.T. Press, 1983, pp. 95-136.

[4] V. Olgyay, Design with Climate, Princeton University Press, Princeton, 1973, p. 7.

[5] R. Tang, I. Meir, Y. Etzion, Thermal Behavior of Buildings with Curved Roofs as Compared with Flat Roofs, Solar Energy, Vol. 74, 2003, pp. 273-286.

[6] A. K. Faghih, M. N. Bahadori, Three Dimensional Numerical Investigation of Air Flow over Domed Roofs, J Wind Eng Ind Aerod, Vol. 98, 2010, pp. 161-168.

[7] A. K. Faghih, M. N. Bahadori, Experimental Investigation of Air Flow over Domed Roofs, Iranian J of Science and Technology; Engineering, Vol. 33, 2009, pp. 207-216.

[8] A. K. Faghih, M. N. Bahadori, Solar Radiation on Domed Roofs, Energy and Buildings, Vol. 41 (B3), 2009, pp. 1238-1245.

[9] M. Yazdanian, J. Klems, Measurement of the Exterior Convective Film Coefficient for Windows in Low-rise Buildings, ASHRAE Transactions 100 (1), 1994, pp. 1087-1096.

[10]A. D. Penwarden, Wise, Wind Environment around Buildings, Bldg. Res. Estab., 1975.

[11]ASHRAE, ASHRAE Handbook-Fundamentals, American Society of Heating, Refrigerating, and Air-conditioning Engineers, Inc., Atlanta, 1997.

[12]M. N. Bahadori, Chamberlain, Simplification of Weather Data to Evaluate Daily and Monthly Energy Needs of Residential Buildings, Sol Energy, Vol. 36, 1986, pp. 499-507.

[13]Berdahl, Fromberg, the Thermal Radiance of Clear Skies, Solar Energy, Vol. 29, p. 299.

[14]E. Ahmadi, Heat Transfer Analysis in Ground, M.S. Thesis (in Persian), School of Mechanical Engineering, Sharif University of Technology, 1999. 